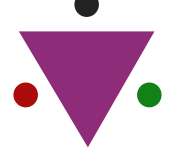

IJCRR

Section: Healthcare

Sci. Journal Impact

Factor: $6.1(2018)$

ICV: 90.90 (2018)

(c) (1) (9)

Copyright@IJCRR

\title{
Relationship of Neutrophil-to-Lymphocyte Ratio with Anastomosis Leakage as Complication of Colorectal Surgery in Colorectal Cancer Patients
}

\author{
Anang Auric Yuliandar, Muhammad Iwan Dani, Bambang Suprapto, Prihantono
}

Department of Surgery, Faculty of Medicine, Hasanuddin University, Makassar, Indonesia

\section{ABSTRACT}

Background: The literature examining the relationship between the elevated neutrophil-to-lymphocyte ratio (NLR) and the incidence of postoperative complications is varied. The primary object of this investigation was to determine the relationship between the NLR with the occurrence of the anastomotic leak as a complication after colorectal surgery in colorectal cancer patients.

Methods: This is observational cross-sectional study of 54 patients with colorectal cancer patients underwent elective surgery at the Central Operating Theatre Abdul Wahab Sjahranie Hospital, Samarinda, Indonesia, in 2018-2019. Lymphocytes and neutrophils are taken from complete blood count values of colorectal cancer patients one day before colorectal surgery. Univariate analysis was carried out to describe the characteristics of the subjects. Bivariate analysis is performed using the independent t-test if the data is normally distributed.

Results: Mean neutrophil value was significantly higher in subjects with anastomotic leakage than in those without a leak, which was 9.91 compared to 5.44 ( $p<0.05$ ). The mean value of percentages of lymphocytes was significantly $(p<0.05)$ lower in subjects with anastomotic leakage compared to those without leakage, which was 14.50 compared to 30.15. The mean NLR value was found to be higher in subjects with anastomotic leak compared to those without leakage, which was 8.60 compared to 5.17 although it was not statistically significant $(p>0.05)$.

Conclusions: There is no relationship between NLR values and complications of postoperative colorectal anastomosis leak in colorectal cancer patients. The mean NLR value was found to be higher in subjects who experienced anastomotic leak compared to those without leakage. The neutrophil rate was significantly higher and the lymphocyte rate was lower in subjects who experienced anastomotic leakage compared to those without leakage.

Key Words: Colorectal cancer, Anastomosis leakage, Neutrophil-to-lymphocyte ratio, Lymphocyte, Complication

\section{INTRODUCTION}

Colorectal Cancer (CRC) is still a big problem in the world in general and in Indonesia in particular. CRC is the third most common cancer of all cancers and the second leading cause of cancer-related deaths for men and women in the United States. According to the American Cancer Society, 135,430 new cases, and 50,260 deaths from colorectal cancer are estimated to occur in 2017, and the lifetime risk of developing a CRC is around 1 in $21(4.7 \%)$ for men and 1 in $23(4.4 \%)$ for the woman. In Indonesia, the incidence of colorectal cancer is 12.1 per 100,000 adult population, with a mortality of $9.1 \%$ of all cancer cases. ${ }^{1,2}$
Comprehensive management of CRCs is very important because of the high number of cases and high mortality rates with high health care costs. The CRC treatment strategy is chemotherapy and surgery. Local tumor control by surgery is generally the main treatment to prevent local tumor complications, such as postoperative obstruction, perforation or leakage of anastomosis, fistula formation, and infection. Even with metastases in the liver or lungs, primary tumor resection remains a priority. ${ }^{3}$

Overall surgical mortality in 30 days after colorectal resection is between 3.5 and $6 \%$, with less than $2 \%$ after elective surgery but up to $20 \%$ after emergency surgery. Intraoperative complications such as injury to relevant anatomic

\section{Corresponding Author:}

Prihantono, Department of Surgery, Faculty of Medicine, Hasanuddin University, Makassar, Indonesia. Email: prihantono@pasca.unhas.ac.id

ISSN: 2231-2196 (Print)

Received: 15.08 .2020
ISSN: 0975-5241 (Online)

Revised: 05.09 .2020
Accepted: 10.10 .2020
Published: 24.11 .2020 
structures such as the ureter, spleen, intestine, and duodenum are related to surgical techniques. Specific complications of early surgery include bleeding, most often within the first few days of resection, nonspecific infection, or infection associated with the anastomotic leak. Other complications that are more common in the early postoperative period (days after surgery 1-3) are commonly related to the cardiopulmonary system and include lung problems (eg, atelectasis, pneumonia, aspiration, and pulmonary embolism) and cardiac events (for example, arrhythmias, ischemia myocardial and dysfunction). Intra-abdominal complications consist of delayed return of an upper and lower gastrointestinal function (postoperative ileus), dehiscence of the surgical wound, and anastomotic leak. ${ }^{4}$

Clinical leakage occurs in 1-2\% of all colonic resections, but subclinical leakage is more frequent and may be seen incidentally in contrast studies among asymptomatic patients. The anastomotic leak can present with symptoms such as fever, tachycardia, abdominal distension, ileus, faecal discharge through drainage or sores, or local and general peritonitis. Occasionally, leakage can occur with sudden damage, general peritonitis, and septic shock as a result of significant and rapid contamination of the peritoneal cavity. Because of unspecific symptoms, leakage should be suspected in patients who do not experience the expected healing progress. Routine blood examination parameters such as white blood cell count and C-reactive protein may be increased but not specific and difficult to distinguish from normal postoperative reactions. Postoperatively, free air in the stomach should normally be absorbed within 7-10 days. The presence of subdiaphragmatic free air on abdominal radiograph examinations is suspicion for the anastomotic leak. 4,5

Many epidemiological studies show that chronic inflammation is a predisposing factor for various types of cancer. The neutrophil-to-lymphocyte ratio (NLR) has emerged as a marker to characterize the body's inflammatory status. Derived from a patient's routine complete blood count (CBC), the division of the absolute neutrophil count by the absolute lymphocyte count yields the NLR. ${ }^{6,7}$ Inflammation affects all stages of tumour development and the infiltration of inflammatory cells and increased expression of pro-inflammatory mediators has been reported in colorectal cancer. Transformed epithelial cells produce and secrete inflammatory mediators such as chemokines and pro-inflammatory cytokines (for example, IL-1b, TNF-a). Increased neutrophil counts will increase tumour growth and metastasis by remodelling the extracellular matrix, releasing reactive oxygen species, and suppressing lymphocyte activity. ${ }^{8}$

The literature examining the relationship between elevated NLR and the incidence of postoperative complications is varied. Cook et al.was the first to show that high NLR on a postoperative day was associated with postoperative compli- cations. This finding is supported by Kubo et al, who found that infectious complications were significantly related to NLR. Similarly, Gohil et al. reported that preoperative NLR values were associated with an increase in hospital stays. Josse et al. investigated the role of NLR on complications of an anastomotic leak involving 583 patients in a retrospective cohort study. With ROC curve analysis the results of preoperative NLR values greater than or equal to 2.3 are significantly associated with major perioperative complications. However, no association was found between preoperative NLR and the type of complications, although there was a tendency for the anastomotic leak. ${ }^{6,7,9}$

The primary objective of this investigation was to determine the relationship between the neutrophil-to-lymphocyte ratio with the occurrence of the anastomotic leak as a complication after colorectal surgery in colorectal cancer patients.

\section{MATERIALS AND METHODS}

The design of this study was observational analytic using a cross-sectional study design. Data were obtained from the patient's medical record. The data collection was conducted from January-April 2019. This research has been approved by the Research Ethics Committee, Mulawarman University, Samarinda, Indonesia, with approval letter no.101/KEPKAWS/V/2019.

\section{Patient Population}

The study population of this research was colorectal cancer patients who underwent elective surgery at the Central Operating Theatre Abdul Wahab Sjahranie Hospital, Samarinda, Indonesia, in 2018-2019. The sampling method used was non-probability sampling with purposive sampling. The inclusion criteria for this study were subjects diagnosed with colorectal cancer (new patients and old patients) who underwent elective surgery at the Central Operating Theatre Abdul Wahab Sjahranie Hospital, Samarinda, Indonesia, with laparotomy surgery, and colorectal surgery with primary resection and anastomosis. The exclusion criteria were incomplete patient medical record data, primary anastomosis with a protective stoma, and surgery without anastomosis (Hartmann procedure, palliative stoma, by-pass anastomosis).

In this research, colorectal cancer patients are defined as patients who were diagnosed clinically, and pathologically. The diagnosis is made by a surgeon at Abdul Wahab Sjahranie Hospital. Patients with complications of the anastomotic leak are patients who have been diagnosed with anastomotic leak found significantly during re-surgery. Lymphocytes and neutrophils are taken from complete blood count values of colorectal cancer patients one day before colorectal surgery. NLR values are absolute neutrophil values compared to absolute lymphocyte values in each colorectal cancer patient 
before undergoing surgery. The normal value of NLR in this study is between 0.78 to 3.58 .

\section{Statistical Analysis}

The number of samples was determined using the binomial proportions formula, and the result was 57 samples. The data normality test used the Kolmogorov-Smirnov test (respondents over 50) with normally distributed data if the pvalue $>0.05$. Univariate analysis was carried out to describe the characteristics of the subjects. Bivariate analysis is performed using the independent t-test if the data is normally distributed or alternative test, using the ANOVA test to determine differences in values, diagnostic tests according to the variables studied.

\section{RESULT}

From data taken from the medical record at Abdul Wahab Sjahranie Hospital Samarinda in the January 2018 - January 2019 period, 54 patients were included in this study. The categorical variables of this study were presented in Table 1.

\section{Table 1: Baseline Characteristics}

\begin{tabular}{llcc} 
Category & Variable & n & $\%$ \\
Sex & Male & 31 & 57,4 \\
& Female & 23 & 42,6 \\
Age & <40 years & 7 & 13,0 \\
& 40-49 years & 12 & 22,2 \\
& 50-59 years & 18 & 33,3 \\
& 6o-69 years & 12 & 22,2 \\
Anastomosis leakage & Yes & 5 & 9,3 \\
& No & 14 & 25,9 \\
Type of surgery on a & Hemicolectomy Sinistra & 3 & 21.4 \\
patient with anasto- & Hemicolectomy Dextra & 1 & 7.1 \\
mosis leakage & Lower anterior resection & 7 & 50 \\
& Sigmoidectomy & 3 & 21.4 \\
Status & Deceased & 7 & 13,0 \\
& Alive & 47 & 87,0 \\
\hline
\end{tabular}

From Table 1, the number of subjects was 54 patients, with $31(57.4 \%)$ men and $23(42.6 \%)$ women. The age of the subjects were $<40$ years on $7(13 \%), 40-49$ years on $12(22.2 \%)$, $50-59$ years on $18(33.3 \%), 60-69$ years on $12(22.2) \%),>70$ years on $5(9.3 \%)$ subjects. The number of CRC cases that were operated on and experienced anastomotic leakage was found in $14(25.9 \%)$ patients. The distribution of types of surgery with the anastomotic leak was found to be $3(21.4 \%)$ of hemicolectomy sinistra, and $1(7.1 \%)$ of hemicolectomy dextra, 7 (50.0\%) lower anterior resections, and sigmoidectomy were $3(21.4 \%) \%$ ) cases. Patient status was $7(13.0 \%)$ died, and $47(87.0 \%)$ lived.

Table 2 shows the descriptive statistics of numerical variables. Age of subjects between 23-79 years with an average of $53.4 \pm 12.1$ years. Neutrophil value of $0.10-25.20$ with an average of $6.60 \pm 5.6$, the value of lymphocytes $0.24-19.1$ with an average of $2.2 \pm 3.29$, and an NLR value of 0.01 44.75 with a mean $6.06 \pm 8.45$.

\begin{tabular}{lcccc}
\multicolumn{4}{l}{ Table 2: Numeric Variables Characteristics $(\mathbf{n = 5 4})$} \\
Variables & Minimum & Maximum & Mean & SD \\
Age & 23 & 79 & 53,37 & 12,06 \\
Neutrophil & 0,10 & 25,20 & 6,60 & 5,54 \\
\% Neutrophil & 3 & 96 & 63,70 & 23,00 \\
Lymphocyte & 0,24 & 19,10 & 2,22 & 3,29 \\
\% Lymphocyte & 3 & 89 & 26,09 & 20,37 \\
NLR & 0,01 & 44,75 & 6,06 & 8,45 \\
\hline
\end{tabular}

The results of normality test data stated in Table 3, the value of Kolmogorov-Smirnov Z is 0.529 and $p=0.942(p>0.05)$, thus the data are normally distributed.

\begin{tabular}{llc} 
Table 3: Kolmogorov-Smirnov Normality Test & $\begin{array}{c}\text { Unstandard- } \\
\text { ized Residual }\end{array}$ \\
N & Mean & 54 \\
Normal Parameters' & o \\
& Std. Deviation & 13.58936478 \\
Most Extreme Differences & Absolute & 0.072 \\
& Positive & 0.072 \\
Kolmogorov-Smirnov Z & Negative & -0.07 \\
Asymp. Sig. (2-tailed) & & 0.529 \\
\hline
\end{tabular}

\section{Leulocyte measurement in colorectal cancer patients}

Table 4 shows that statistically, the mean neutrophil value was significantly higher in subjects with anastomotic leakage than in those without a leak, which was 9.91 compared to $5.44(\mathrm{p}<0.05)$. Then the mean value of\%neutrophil was significantly higher in subjects with anastomotic leakage compared to those without leakage, which was 77.50 compared to $58.88(\mathrm{p}<0.05)$. The mean value of lymphocytes being lower in subjects with anastomotic leakage compared to those without leakage, but not statistically significant $(\mathrm{p}>$ 0.05 ). The mean value of $\%$ lymphocytes was significantly ( $p$ $<0.05$ ) lower in subjects with anastomotic leakage compared to those without leakage, which was 14.50 compared to 30.15. The mean NLR value was found to be higher in sub- 
jects with anastomotic leak compared to those without leakage (Figure 1), which was 8.60 compared to 5.17 although it was not statistically significant $(\mathrm{p}>0.05)$.

Table 4: Average neutrophils, lymphocytes, and NLR according to Anastomotic Leakage

\begin{tabular}{llcccc} 
Variables & $\begin{array}{l}\text { Anastomosis } \\
\text { Leakage }\end{array}$ & $\mathbf{n}$ & Mean & SD & $\mathbf{p}^{*}$ \\
Neutrophil & Yes & 14 & 9,91 & 5,97 & 0,008 \\
& No & 40 & 5,44 & 4,95 & \\
\% Neutrophil & Yes & 14 & 77,50 & 10,90 & 0,000 \\
& No & 40 & 58,88 & 24,22 & \\
Lymphocyte & Yes & 14 & 1,36 & 0,37 & 0,258 \\
& No & 40 & 2,52 & 3,78 & \\
\% Lymphocyte & Yes & 14 & 14,50 & 7,93 & 0,000 \\
& No & 40 & 30,15 & 21,86 & \\
NLR & Yes & 14 & 8,60 & 7,86 & 0,183 \\
& No & 40 & 5,17 & 8,56 & \\
\hline
\end{tabular}

* Independent t-test

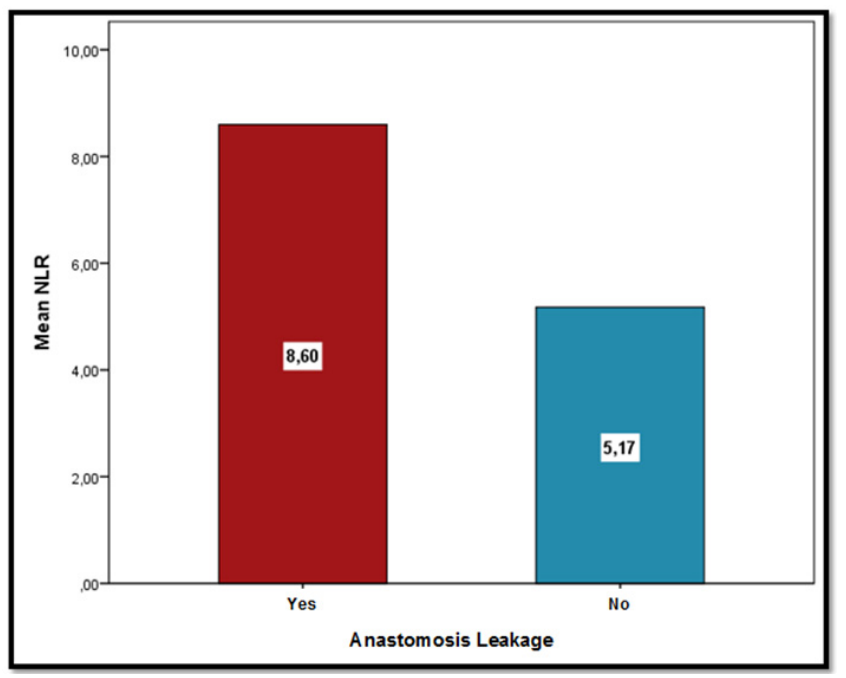

Figure 1: Comparison of NLR according to Anastomotic Leaks.

\section{Relationaship of leukocyte with survival status}

Table 5 shows the mean neutrophil values higher in subjects who deceased than in living subjects, but not statistically significant ( $p>0.05$ ). The mean\% of neutrophils was higher in subjects who deceased than in living subjects, but not statistically significant ( $p>0.05$ ). The lymphocyte rate was lower in deceased subjects compared to living subjects, but not statistically significant $(\mathrm{p}>0.05)$. The mean $\%$ of lymphocytes was lower in deceased subjects than in living subjects, but not statistically significant ( $\mathrm{p}>0.05)$. The mean NLR was found to be higher in subjects who were deceased than in living subjects (Figure 2), which was 14.43 compared to 4.81 although it was not statistically significant ( $\mathrm{p}>0.05)$.
Table 5: Mean neutrophils, lymphocytes, and NLR according to survival status

\begin{tabular}{llcccc} 
Variables & Status & n & Mean & SD & p \\
Neutrophil & Deceased & 7 & 10,83 & 8,68 & 0,193 \\
& Alive & 47 & 5,97 & 4,73 & \\
\% Neutrophil & Deceased & 7 & 77,29 & 16,97 & 0,094 \\
& Alive & 47 & 61,68 & 23,23 & \\
Lymphocyte & Deceased & 7 & 1,12 & 0,54 & 0,346 \\
& Alive & 47 & 2,38 & 3,50 & \\
\% Lymphocyte & Deceased & 7 & 15,57 & 11,80 & 0,145 \\
& Alive & 47 & 27,66 & 20,99 & \\
NLR & Deceased & 7 & 14,43 & 16,73 & 0,181 \\
& Alive & 47 & 4,81 & 5,78 & \\
\hline
\end{tabular}

* Independent t-test

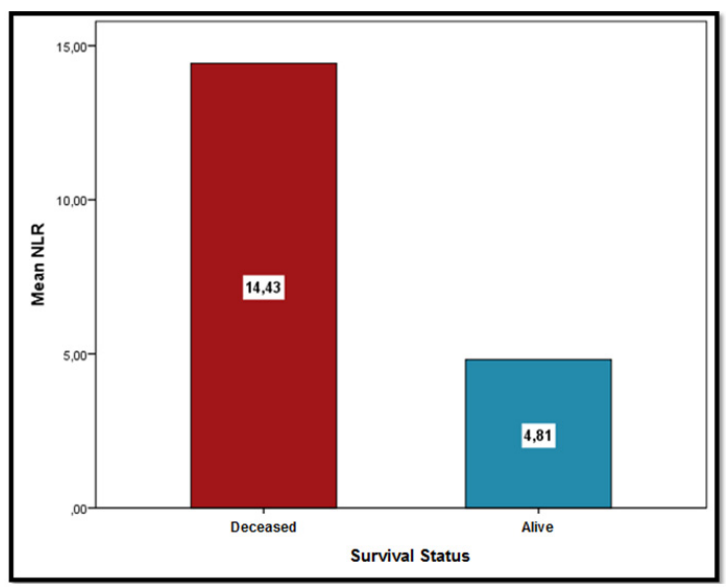

Figure 2: Comparison of NLR according to Survival Status

Table 6 stated that in subjects who had anastomotic leakage, the mean NLR was higher in deceased subjects (11.72) than in living subjects (7.35), but not statistically significant $(\mathrm{p}>0.05)$.In subjects without anastomotic leakage, the mean NLR was found to be higher in deceased subjects (18.04) than in living subjects (4.13), but not statistically significant $(\mathrm{p}>0.05)$ (Figure 3).

Table 6: Average neutrophils, lymphocytes, and NLR according to Patient Status and Anastomotic Leaks

$\begin{array}{lllllll}\begin{array}{l}\text { Anasto- } \\ \text { mosis } \\ \text { leakage }\end{array} & \text { Variables } & \begin{array}{l}\text { Survival } \\ \text { Status }\end{array} & \text { n } & \text { Mean } & \text { SD } & \mathbf{p}^{*} \\ \text { Yes } & \text { Neutrophil Deceased } & 4 & 12,50 & 9,77 & 0,518 \\ & & \text { Alive } & 10 & 8,87 & 3,94 & \\ & \begin{array}{l}\text { \% Neutro- } \\ \text { phil }\end{array} & \text { Deceased } & 4 & 79,75 & 14,43 & 0,644 \\ & & \text { Alive } & 10 & 76,60 & 9,96 & \end{array}$


Table 6: (Continued)

\begin{tabular}{|c|c|c|c|c|c|c|}
\hline $\begin{array}{l}\text { Anasto- } \\
\text { mosis } \\
\text { leakage }\end{array}$ & Variables & $\begin{array}{l}\text { Survival } \\
\text { Status }\end{array}$ & $\mathbf{n}$ & Mean & SD & $\mathbf{p}^{*}$ \\
\hline \multirow{16}{*}{ No } & \multirow{2}{*}{$\begin{array}{l}\text { Lympho- } \\
\text { cyte }\end{array}$} & Deceased & 4 & 1,32 & 0,53 & \multirow[t]{2}{*}{0,849} \\
\hline & & Alive & 10 & 1,37 & 0,31 & \\
\hline & \multirow{2}{*}{$\begin{array}{l}\text { \% Lym- } \\
\text { phocyte }\end{array}$} & Deceased & 4 & 12,75 & 7,76 & \multirow[t]{2}{*}{0,621} \\
\hline & & Alive & 10 & 15,20 & 8,30 & \\
\hline & \multirow[t]{2}{*}{ NLR } & Deceased & 4 & 11,72 & 13,13 & \multirow[t]{2}{*}{0,559} \\
\hline & & Alive & 10 & 7,35 & 5,07 & \\
\hline & \multirow[t]{2}{*}{ Neutrophil } & Deceased & 3 & 8,60 & 8,36 & \multirow[t]{2}{*}{0,255} \\
\hline & & Alive & 37 & 5,18 & 4,67 & \\
\hline & \multirow{2}{*}{$\begin{array}{l}\% \text { Neutro- } \\
\text { phil }\end{array}$} & Deceased & 3 & 74,00 & 22,87 & \multirow[t]{2}{*}{0,266} \\
\hline & & Alive & 37 & 57,65 & 24,21 & \\
\hline & \multirow{2}{*}{$\begin{array}{l}\text { Lympho- } \\
\text { cyte }\end{array}$} & Deceased & 3 & 0,85 & 0,50 & \multirow[t]{2}{*}{0,433} \\
\hline & & Alive & 37 & 2,66 & 3,90 & \\
\hline & \multirow{2}{*}{$\begin{array}{l}\text { \% Lym- } \\
\text { phocyte }\end{array}$} & Deceased & 3 & 19,33 & 17,04 & \multirow[t]{2}{*}{0,380} \\
\hline & & Alive & 37 & 31,03 & 22,16 & \\
\hline & \multirow[t]{2}{*}{ NLR } & Deceased & 3 & 18,04 & 23,39 & \multirow[t]{2}{*}{0,411} \\
\hline & & Alive & 37 & 4,13 & 5,83 & \\
\hline
\end{tabular}

* Independent t-test

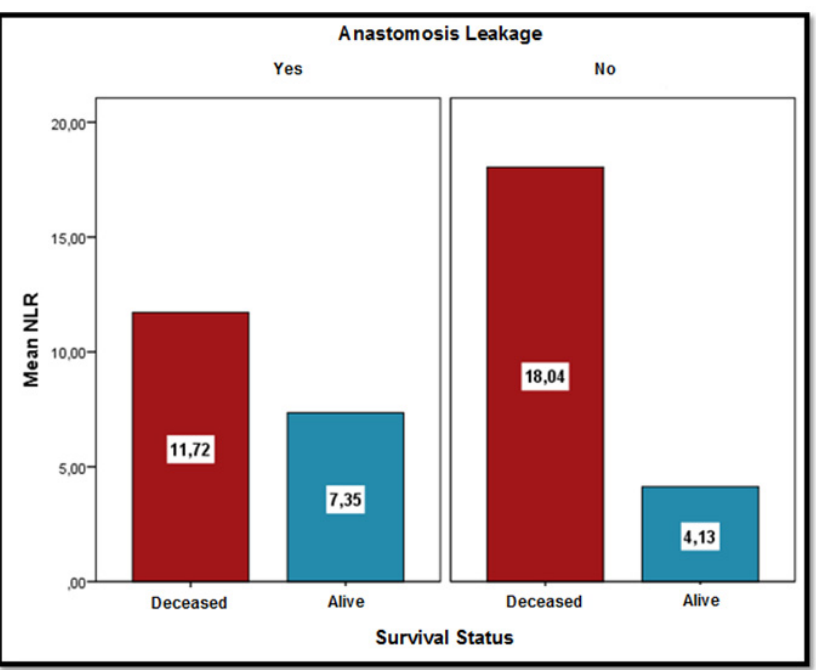

Figure 3: Comparison of NLR according to Anastomotic Leakage and Patient Status.

\section{DISCUSSION}

In this study, the highest age distribution was 50 - 59 years as many as $18(33.3 \%)$ with an age range of 23-79 years with an average of $53.4 \pm 12.1$ years. According to theory, the incidence of $\mathrm{CRC}$ began to increase after the age of 35 years and increased rapidly after the age of 50 years, its peak in the seventh decade. More than $90 \%$ of colon cancer occurs after the age of 50 years. The number of samples of CRC patients in this study was 54, 31 (57.4\%) men, and $23(42.6 \%)$ women. This compares to the ACS survey, in 2018, as many as 25,920 cases of CRC were estimated to occur in men and 17,110 in women. ${ }^{10}$

NLR values in this study were obtained in the range of 0.01 44.75 with a mean of $6.06 \pm 8.45$. Forget et al. determined the limits of normal NLR values observed in adult, non-geriatric populations, without acute illness and/or chronic disease and it has been identified that the normal NLR value in the adult population, which is between 0,78 and 3.53. Described by Walsh et al., NLR value of around 5 is believed to reflect an increase in inflammatory status in patients with CRC, this is in line with the results of the study, where the mean NLR value was found to be higher in subjects who experienced anastomotic leak compared to those who did not experience an anastomotic leak, which was 8.60 compared to 5.17 even though it was not statistically significant $(p>0.05) .{ }^{11,12}$

A preoperative NLR value greater than or equal to 2.3 was significantly associated with the main complications after CRC, one of which was an anastomotic leak. In a study by Walker et al. $136 \mathrm{CRC}$ patients with a mean age of 64.5 years, who underwent colorectal resection with primary anastomosis in Fremantle and Fiona Stanley Austalia Hospital during the period January 2014 to January 2016, were obtained NLR values above 5.05 from 11 patients experiencing anastomotic leakage. ${ }^{13}$

In this study, the distribution of types of operations with anastomotic leakage, dextra hemicolectomy was $7.1 \%$, Sinistra hemicolectomy $21.4 \%$, sigmoidectomy $21.4 \%$ and lower anterior resection 50.0\%. Schiff et al. examining 156 surgeons from eight countries, 458 patients underwent colorectal surgery with an anastomotic leak identified in the circular anastomosis. A statistically significant relationship was observed between the location of the anastomosis and the occurrence of postoperative anastomosis leakage. The leak was observed more frequently in patients with the rectum and sigmoid anastomosis (49 of 62 patients with postoperative leakage, $79.0 \%$ ) than in patients with colonic anastomosis (13 patients, $21.0 \%){ }^{14}$

Several studies have evaluated various risk factors for anastomotic leakage, but there is no universal agreement regarding related risk factors, although it is generally considered that anastomosis with lower anastomosis levels is associated with leakage. Shelgyn et al. examined the role of NLR in diagnosing the anastomotic leak in $100 \mathrm{CRC}$ patients undergoing low anterior resection surgery (LAR), found $20 \%$ of patients experienced leakage with NLR values ranging from 6.8 to $7.6 .{ }^{15}$ There are several possible explanations for this association between increased NLR and poor oncological outcomes, Ding et al. mentioning the host immune response to a tumour depends on lymphocytes. First, an increase in 
tumour lymphocytes in primary tumours has a good predictor for a good prognosis. Second, increased neutrophils can cause a strong increase of pro-angiogenic factors that act directly on the area near the blood vessels to promote the growth and development of neoplasm cells. Therefore, NLR can be considered as a balance between the inflammatory status of the protumor and the immune status of the antitumor. ${ }^{16}$

Further research is needed by using lymphocyte and serial neutrophil values as well as a larger sample size, to assess the relationship of NLR with complications of leakage of postoperative colorectal anastomosis in CRC patients to obtain significant research results. Further research is also needed on other factors associated with complications of leakage of post-colorectal anastomosis in CRC patients.

\section{CONCLUSION}

The mean NLR value was found to be higher in subjects who experienced anastomotic leak compared to those without leakage. The neutrophil rate was significantly higher and the lymphocyte rate was lower in subjects who experienced anastomotic leakage compared to those without leakage. Further investigation is needed regarding the relationship and role of NLR values with complications of postoperative leakage of colorectal anastomoses in colorectal cancer patients.

\section{REFERENCES}

1. Siegel RL, Miller KD, Fedewa SA, Ahnen DJ, Meester RGS, Barzi A, et al. Colorectal cancer statistics, 2017. CA Cancer J Clin 2017;67(3):177-93.

2. Bray F, Ferlay J, Soerjomataram I, Siegel RL, Torre LA, Jemal A. Global cancer statistics 2018: GLOBOCAN estimates of incidence and mortality worldwide for 36 cancers in 185 countries. CA Cancer J Clin 2018;68(6):394-2.

3. Lisle D, Lee-Kong S. Surgical Management of Complicated Colon Cancer. Clin Colon Rectal Surg 2015;28(04):228-33.
4. Ashley SW. Maingot's Abdominal Operations. 13thth ed. McGraw-Hill Education / Medical; 2019.

5. Tang CL, Yeong KY, Nyam DC, Eu KW, Ho YH, Leong AF, et al. Postoperative intra-abdominal free gas after open colorectal resection. Dis Colon Rectum 2000;43(8):1116-20.

6. Josse JM, Cleghorn MC, Ramji KM, Jiang H, Elnahas A, Jackson TD, et al. The neutrophil-to-lymphocyte ratio predicts major perioperative complications in patients undergoing colorectal surgery. Colorectal Dis 2016;18(7): O236-O242.

7. Cook EJ, Walsh SR, Farooq N, Alberts JC, Justin TA, Keeling NJ. Post-operative neutrophil-lymphocyte ratio predicts complications following colorectal surgery. Int J Surg 2007;5(1):27-30.

8. Kwon HC, Kim SH, Oh SY, Lee S, Lee JH, Choi HJ, et al. Clinical significance of preoperative neutrophil-lymphocyte versus platelet-lymphocyte ratio in patients with operable colorectal cancer. Biomarkers 2012;17(3):216-22.

9. Kubo T, Ono S, Ueno H, Shinto E, Yamamoto J, Hase K. Impact of the perioperative neutrophil-to-lymphocyte ratio on the long-term survival following an elective resection of colorectal carcinoma. Int J Colorectal Dis 2014;29(9):1091-9.

10. Bénard F, Barkun AN, Martel M, von Renteln D. A systematic review of colorectal cancer screening guidelines for averagerisk adults: Summarizing the current global recommendations. World J Gastroenterol 2018;24(1):124-38.

11. Forget P, Khalifa C, Defour JP, Latina D, Van Pel MC, De Kock $\mathrm{M}$. What is the normal value of the neutrophil-to-lymphocyte ratio?. BMC Res Notes 2017;10(1):12.

12. Walsh S, Cook E, Goulder F, Justin T, Keeling N. Neutrophillymphocyte ratio as a prognostic factor in colorectal cancer. J Surg Oncol 2005;91(3):181-4.

13. Walker PA, Kunjuraman B, Bartolo DCC. Neutrophil-to-lymphocyte ratio predicts anastomotic dehiscence. ANZ J Surg 2018;88(7-8): E573-E577.

14. Schiff A, Roy S, Pignot M, Ghosh SK, Fegelman EJ. Diagnosis and Management of Intraoperative Colorectal Anastomotic Leaks: A Global Retrospective Patient Chart Review Study. Surg Res Pract 2017;2017:1.

15. Shelygin YA, Tarasov MA, Zarodnyuk IV, Nagudov MA, Alekseev MV, Rybakov EG. The Role Of Neutrophil-To-Lymphocyte Ratio (Nlr) In The Diagnosis Of Low Colorectal Anastomosis Leakage. Koloproktologiâ. 2017;(4):74-1.

16. Ding PR, An X, Zhang RX, Fang YJ, Li LR, Chen G, et al. Elevated preoperative neutrophil to lymphocyte ratio predicts risk of recurrence following curative resection for stage IIA colon cancer. Int J Colorectal Dis. 2010;25(12):1427-33. 